\title{
Regulatory strategies to reduce tobacco addiction in youth
}

\author{
J E Henningfield, E T Moolchan, M Zeller
}

Tobacco Control 2003;12(Suppl I):i14-i24

Preventing tobacco addiction and achieving cessation in established users are the cornerstones of efforts to reduce tobacco use and disease. It has been increasingly recognised that reducing tobacco toxin exposure has theoretical potential to reduce disease in continuing tobacco users. This has been controversial because such approaches also carry the potential to undermine prevention and cessation. As complicated as harm reduction issues are for adults, they are still more complicated for youth. Harm reduction is not a singular approach, but rather a concept that encompasses an extremely diverse array of potential approaches. These carry equally diverse potential risks and benefits. The regulatory framework (for example, whether or not the Food and Drug Administration regulates the approach) is also predicted to be a major factor in determining the consequences of harm reduction approaches. This paper examines the various issues and potential approaches concerning the application of harm reduction to youth. We conclude that although some carry great risk, others may actually support broader tobacco control efforts to prevent tobacco use and foster cessation in youth and adults.

See end of article for authors' affiliations

Correspondence to:

Correspondence to:
Jack E Henningfield, PhD, Pinney Associates,

4800 Montgomery Lane

Suite 1000, Bethesda, MD

20814, USA;

jhenning@

pinneyassociates.com
$\mathrm{D}$ ata from the US National Household Survey on Drug Abuse indicates that every day in the year 2000, approximately 5000 adolescents tried smoking, and 2100 adolescents graduated to daily smoking levels, ${ }^{1}$ of which it can be projected that approximately a third will prematurely die of tobacco caused disease. ${ }^{2}$ Although smoking initiation among youth declined from 1997 to 2001, ${ }^{3}$ smoking initiation among youth remains the primary pipeline to adult smoking and disease. This results in approximately 400000 deaths per year that can be projected to continue for decades to come without radical changes in the prevalence of tobacco use and the level of toxin exposure in continuing users, as shown in fig $1{ }^{4}$

Figure 1 shows that preventing initiation is important to long term disease, but in the short run cessation will have more profound effects because of the relatively rapid reduction of risk of disease following cessation. ${ }^{4}$ Thus, preventing initiation and fostering cessation are cornerstones in the foundation for tobacco control efforts. ${ }^{5}$

For addicted adult tobacco users, a third component has been increasingly discussed, which is to find ways to reduce the exposure to tobacco toxins in persons who are unable to achieve complete tobacco and nicotine cessation..$^{6-9}$ This approach is often labelled "harm reduction" and we will use that term in this paper, although we are aware that the term has also been used to describe liberalised access to illicit drugs, which we do not endorse. This paper will explore the possibility of reducing the risk of disease by incorporating harm reduction approaches into youth focused tobacco control efforts. Our intent is to provide a systematic basis for evaluating various putative public health approaches to reducing tobacco caused disease.

\section{PUBLIC HEALTH PERSPECTIVE}

Evaluating the risks and benefits of potential tobacco control strategies requires an understanding of the public health context of tobacco use. As shown in fig 2, the tobacco user can be considered the host, and one facing a premature mortality risk up to $50 \%$ if he or she is a lifelong daily cigarette smoker. ${ }^{10}$ The risk of developing dependence and its consequences are related to characteristics of the host (for example, vulnerability), the agent (for example, toxicity and addictiveness), and the vector (for example, tobacco companies use powerful marketing techniques to hype their products). ${ }^{11}$ Environmental factors, including the regulatory environment, social norms, tobacco taxes, and educational interventions, can have an impact on the agent, host, and vector interactions as well. ${ }^{12}$

\section{TOBACCO AND NICOTINE ADDICTION}

\section{Addiction}

Addiction is the general term for what is more technically referred to as dependence. ${ }^{13-15}$ It refers to a pattern of maladaptive drug use that is often chronic, relapsing, and persistent in the face of negative consequences. ${ }^{13} 15$ The majority of adult cigarette smokers in the USA meet criteria for dependence, whereas, with respect to all other drug categories, the majority of users do not meet such criteria. ${ }^{16}$

The development of tobacco addiction is accompanied by the development of tolerance such that over time, progressively larger doses of nicotine produce relatively weak effects compared to when smoking first began. Corresponding to the development of tolerance is escalation in dose intake that may be necessary to achieve the effects initially achieved by lower doses. ${ }^{17}$ Tolerance is often accompanied by the development of physiological dependence such that abrupt termination of nicotine intake is accompanied by the

Abbreviations: AMA, American Medical Association; FDA, Food and Drug Administration; FTC, Federal Trade Commission; IOM, Institute of Medicine; PREPs, potential reduced exposure products 


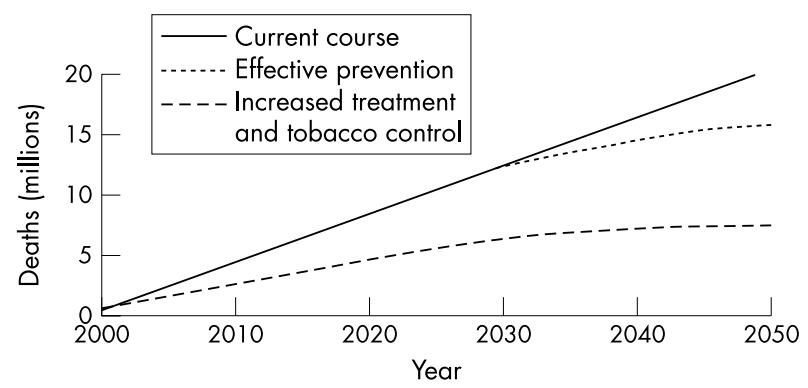

Figure 1 Projected mortality patterns in the USA assuming maintenance of the current course (solid line), immediate major decrease in the initiation of smoking - that is, "effective prevention" (dotted line), and immediate reduction in exposure to tobacco toxins by increased cessation treatment and tobacco control efforts to reduce harm (dashed line). Modified from Henningfield and Slade. ${ }^{4}$

onset of withdrawal signs and symptoms termed a withdrawal syndrome. ${ }^{15}{ }^{16}$ The development of tolerance and of physiological dependence are important because they contribute to the high chronic levels of smoker intake that has such deadly consequences. If tobacco users did not develop nicotine tolerance and physiological dependence, the typical pattern of tobacco use would probably involve far fewer daily exposures, far fewer years of smoking, and less difficulty in achieving cessation.

\section{Tobacco delivered nicotine}

Nicotine is the key addictive chemical in tobacco products; however, many other ingredients may contribute to the overall addictiveness of the products. These include ammonia compounds that can enhance the transfer of nicotine from tobacco to blood stream, acetaldehyde, which can have synergistic reinforcing effects with nicotine, and flavourings that can make it easier to self administer the smoke. ${ }^{18}$ Tobacco delivered nicotine is highly addictive, whereas pure nicotine in medicinal forms carries a relatively low addiction potential and is not the primary health threatening chemical in tobacco. ${ }^{19}$ Thus, it is plausible that moderate levels of nicotine intake might be sustained with relatively little adverse effect, at least compared with tobacco use. This is not to imply that nicotine is without risk; it is a risk factor for heart disease, attention deficit hyperactivity disorder, during pregnancy, and it can lead to the emergence of withdrawal symptoms. ${ }^{19-22}$

The establishment of nicotine addiction in youth should not be taken lightly. ${ }^{23}$ For example, it is not known if all nicotine induced changes in brain structure, such as 300\% increased nicotine receptors in some brain regions ${ }^{24}$ and alteration of brain nicotine reinforcement systems, ${ }^{25}$ are fully reversed following nicotine abstinence in all persons. It is plausible that persisting alterations may confer a continuing need for nicotine in some individuals. ${ }^{46}$ Human drug abusers are also at risk of graduating from "entrée drugs" to more powerful and frequently more toxic forms of drug use, ${ }^{27} 28$ and it is not known if pure nicotine exposure would similarly increase this risk. This may be of little concern for adults who are established cigarette smokers. However, it would be a theoretical risk if the approach was used in non-smoking youth with the goal of preventing the development of cigarette smoking.

\section{Tobacco product type}

Studies of product type have revealed several interesting trends. Smokeless tobacco use tends to start earlier than cigarette smoking and has increased dramatically since the 1970 s. $^{29-32}$ Smokeless tobacco use, in turn, is a risk factor for cigarette smoking. ${ }^{29} 30$ There are also sex and ethnic correlates with various forms of tobacco product use. For example, whereas smokeless tobacco use occurs in males about 10-15 times more frequently than in females, cigar smoking, which increased dramatically among youth in the early 1990s, was substantially less sex specific, although use among males still exceeded that among females. ${ }^{34}$ One prominent factor associated with use of smokeless tobacco and cigars was the perception of low risk relative to smoking (reinforced by the absence of health warnings on cigars and few restrictions on marketing). ${ }^{34}$ Ethnic factors appear relevant but have not been extensively studied for their implications for cessation treatment or for harm reduction strategies. ${ }^{35-37}$

\section{US TOBACCO USE TRAJECTORIES}

Approximately two thirds of adolescents and children try smoking, and within two to three years, approximately a third to a half of those develops patterns of daily use. ${ }^{29}{ }^{30}$ Increased signs of dependence and withdrawal are observed as a function of number of years of smoking, days per month of tobacco use (cigarettes or smokeless), and number of cigarettes per day. ${ }^{27}{ }^{29} 38-40$ A projection of risk data at the population level led the Centers for Disease Control ${ }^{3}$ to conclude that 6.3 million current children and adolescents in the USA will die prematurely because of their tobacco use. Because disease risk is related to amount of tobacco exposure, ${ }^{41}$ the trajectory of tobacco use is an important modulator of disease risk.

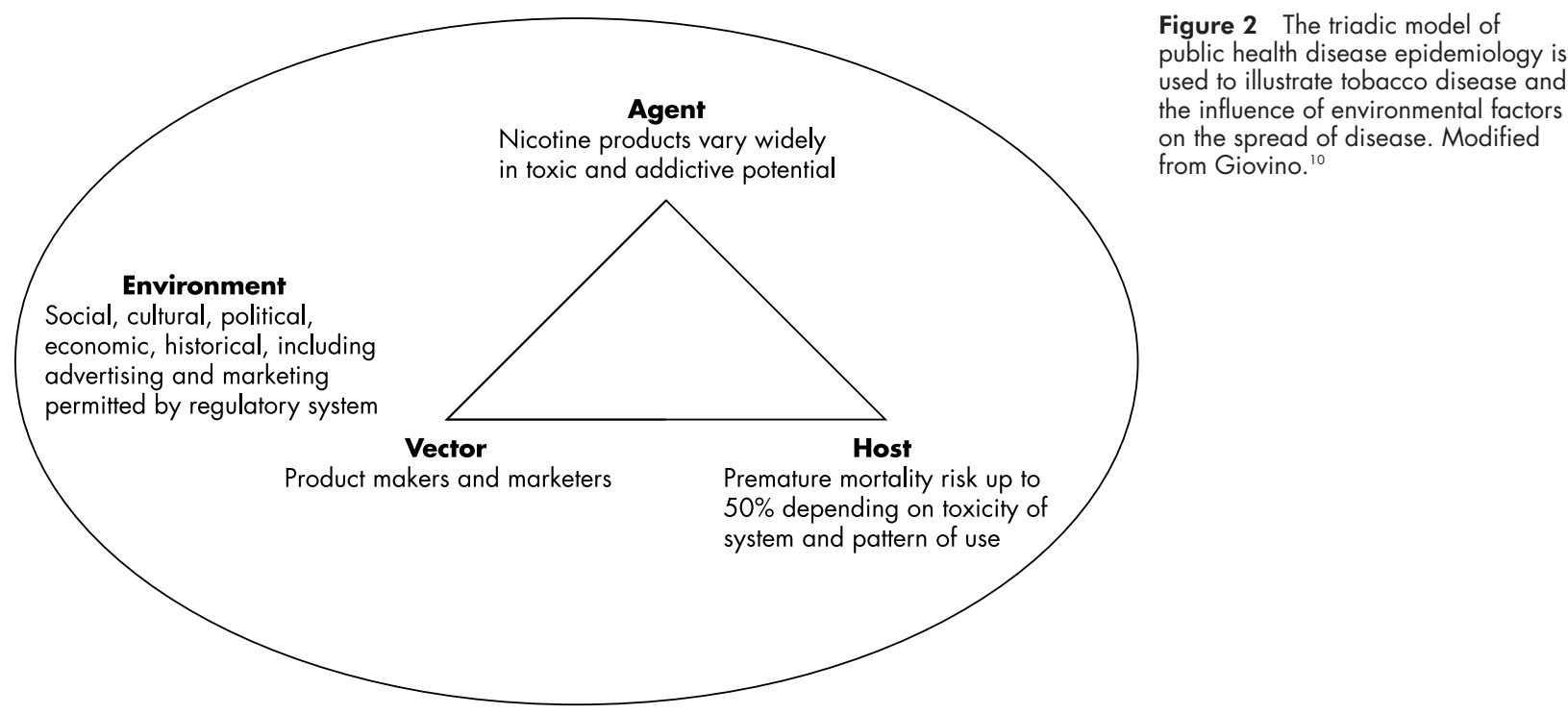


Table 1 Prominent factors associated with the initiation of cigarette smoking and/or development of nicotine dependence 293042

- Tobacco advertising and promotion-for example, hats, lighters, and backpacks with brand logos

- One or more parents smoke, with higher risk if both parents smoke

- Friends use tobacco

- Easy access to tobacco

- Cost is inversely related to initiation and level of use

- Stressful environment

- Attention deficit hyperactivity disorder (ADHD)

- Antisocial behaviour and conduct disorder

- Lower perceptions of harmfulness of tobacco use

- Lower socioeconomic status

Table 1 summarises prominent factors associated with the initiation of cigarette smoking which have been discussed in greater detail elsewhere. ${ }^{29} 3042$ Although the list in the table is not exhaustive, it illustrates that a variety of factors affect the risk of development of dependence. Factors such as distribution of tobacco promotional items have been increasingly studied and found to predict higher rates of graduation from initial smoking to regular smoking. ${ }^{43}$ The parental smoking influence is interesting in that whereas children of parents who smoke are more likely to initiate smoking, cessation by parents also increases the probability that their children will quit. ${ }^{45}$

Following initiation, both pharmacologic (for example, reinforcement, tolerance, and withdrawal) and nonpharmacologic factors determine patterns of use and the risk of further escalation of intake. These factors, which include social support, cost, accessibility, perception of harm, and the palatability of the drug formulation, influence the tendency to increase and maintain drug intake by compensatory changes in self administration behaviour. ${ }^{9} 1546$

\section{Challenges in predicting trajectory}

The fact that most adult smokers are dependent on nicotine, and most began smoking and developed signs of dependence before adulthood, is part of the basis for the categorisation of tobacco dependence as a paediatric disorder. ${ }^{48}{ }^{49}$ However, most youth who try smoking do not develop dependence or continue on into adulthood. ${ }^{29}{ }^{39} 50$ If it were possible to reliably predict which tobacco exposed youth would develop seemingly intractable addictions, which could stop with available treatments, and which would stop with minimal intervention, there would be a stronger foundation for determining which youth might be the most appropriate candidates for riskier interventions-for example, harm reduction strategies that might increase the risk of prolonging the addiction. Progress has been made, but reliable diagnostic approaches to enable such predictions remain elusive. ${ }^{50} 51$

Epidemiological studies show that signs of dependence, such as difficulty quitting and withdrawal, occur in occasional users and can occur within the first few days of smoking initiation, ${ }^{2952}$ although dependence severity tends to be directly related to duration, frequency, and amount of tobacco use. ${ }^{29} 39404253-55$ These uncertainties complicate the evaluation of risk benefit ratios for individualised applications of treatment and harm reduction approaches.

\section{HARM REDUCTION General concepts}

The term "harm reduction" has been applied to many different public health policy and disease control strategies including reducing injuries from motor vehicle accidents, reducing the harms of illicit drug abuse, reducing the spread of
HIV/AIDS, and reducing the harms of tobacco use. Conceptualisations particularly relevant to tobacco control policy have been discussed in detail in a report by the Institute of Medicine (IOM), which was commissioned by the Food and Drug Administration (FDA) to assess the scientific basis for evaluating harm reduction potential in continuing tobacco users. ${ }^{9}$

The fundamental scientific observations that support application of harm reduction approaches to tobacco date to the 1950 s and indicate that the risks of tobacco use are directly related to the amount of tobacco exposure (cigarettes per day) and duration of exposure (years smoking), with duration of smoking carrying the greatest weight in disease risk. ${ }^{41}{ }^{56}$. Earlier onset of tobacco use is also associated with a higher risk of premature mortality. ${ }^{57}$ These observations suggest that among individuals who do smoke, starting later, smoking less, and achieving cessation earlier could reduce the risk of premature death. The observations that even relatively late onset of smoking and smoking fewer than 10 cigarettes per day are associated with an approximately fivefold increase in premature mortality raises a concern regarding harm reduction, namely that if it reduced the effectiveness of efforts to prevent initiation and foster complete cessation, it could contribute to sustained or increased disease by contributing to increased prevalence of tobacco use. ${ }^{97}$ Furthermore, these observations imply that a trajectory of theoretically less toxic tobacco use, which is more persistent than might have otherwise been the case, could carry a higher individual and population disease risk.

\section{Institute of Medicine definition of harm reduction}

The definition of harm reduction adopted in the IOM report ${ }^{9}$ was as follows: "A product is harm reducing if it lowers total tobacco related mortality and morbidity even though use of that product may involve continued exposure to tobacco related toxicants." The report further differentiated three categories of potential harm reduction products: (1) "modified tobacco products" in which certain toxicants (for example, nitrosamine content) are reduced compared to conventional products; (2) "cigarette-like products" in which alternate technologies such as electric and carbon fuelled heating elements reduce overall pyrolysis; and (3) "pharmaceutical products" such as nicotine delivering gum and antidepressants for smoking cessation that are applied to reduce tobacco intake in persons who can not completely abstain from tobacco. To emphasise that the potential of such products to actually achieve the total morbidity and mortality reduction goal is theoretical and has not been conclusively demonstrated, the IOM report used the phrase "potential reduced exposure products" (PREPs) to refer, generically, to these three categories of products.

The IOM report focused mainly on harm reduction approaches for nicotine addicted adult cigarette smokers. It did discuss potential adverse public health consequences for youth, such as the possibility that some harm reduction approaches might produce the unintended consequence of expanding tobacco use prevalence by undermining prevention. Although the report concluded that harm reduction in adults was feasible, it concluded that no such approach has yet been validated in tobacco users, and that potential effects on populations other than those for which the harm reduction approach is intended could lead to an overall adverse public health impact even if certain individuals benefited. The report made it clear that comprehensive regulation of all tobacco products is essential to reduce the death and disease toll from tobacco. It also warned that in the absence of a comprehensive and responsive surveillance system to quickly detect unintended consequences, serious adverse public health effects could emerge which could be difficult to reverse. 


\section{Real world tobacco harm reduction marketing: documented risks}

Risks of harm reduction approaches such as delaying smoking cessation and fostering initiation are not purely theoretical and have been illustrated by the experience with smokeless tobacco products and "light" cigarettes. In both of these cases, the products were at least theoretically less toxic than regular cigarettes but in both cases they appear to have adversely affected public health.

\section{Smokeless tobacco in the USA}

Smokeless tobacco can cause head and neck cancer and other oral diseases and is a risk factor for cigarette smoking and other drug addictions, ${ }^{315859}$ although non-smoked forms of tobacco are less toxic than smoked forms. ${ }^{9}$ In the 1970s, smokeless tobacco was marketed with an implied relative safety campaign that made this tobacco product category the strongest growth business in the 1970s and 1980s and contributed to tobacco use initiation among young people. ${ }^{29} 30$ The campaign included modified products to facilitate initiation (termed "starter" products by the industry) as well as a campaign to foster "graduation" (another industry used term) to stronger products. ${ }^{17}{ }^{60-63}$ The result was a substantial increase in smokeless tobacco use among adolescent males from the 1970s to the present, along with a variety of oral diseases, and increased risk of cigarette smoking, illicit drug abuse, and heavy drinking. ${ }^{29}{ }^{33}$ To date, there has been no documented evidence of a positive contribution to public health in the USA by smokeless tobacco products, and there have been concerns raised that smokeless tobacco products have increased the total harm in the population by fostering tobacco use in persons who would have been unlikely to have smoked cigarettes, or used any smokeless tobacco product (for example, athletes) before the implied safety marketing campaigns. ${ }^{932}$

\section{Smokeless tobacco in Sweden}

It has been argued that smokeless tobacco use in Sweden contributed to reduced cigarette smoking rates. ${ }^{64}$ However, a review of the evidence from Sweden questioned the benefits that could be attributed to snuff and raised serious questions regarding the probability of a favourable benefit to risk ratio if the model were attempted to be extended to the USA. ${ }^{32}$ During the 1970s, Sweden had embarked on a strong public health campaign in which smoking was greatly discouraged and treatment for dependence was increasingly made more readily available. Thus, attributing decreased smoking to a permissive approach to snuff use is not empirically supported though it is a possibility. ${ }^{32}$ It may be many years before it can be concluded whether or not smokeless tobacco contributed to an overall positive public health effect and what the eventual probability of smokeless tobacco users graduating to cigarettes is.

\section{The FTC method and "light" cigarette marketing in the USA}

After the 1964 Surgeon General's report concluded that cancer risk was related to the amount of tobacco exposure, the Federal Trade Commission (FTC) devised a measurement system for the tobacco industry to provide guidance to smokers that was intended to enable them to reduce their exposure to tar and other toxins. ${ }^{6566}$ In the absence of meaningful oversight and controls, the tobacco industry produced cigarettes that yielded much lower values of tar and nicotine by the FTC test method, but sustained high levels of tar and nicotine to cigarette smokers. ${ }^{416768}$ A new category of cigarettes flourished under the guise that they would reduce toxin exposure and hence the risks of smoking-the so-called low tar or light cigarette category-which achieved an approximately two thirds share of the US market by the 1990s. ${ }^{4167-71}$ It was more than three decades before it became clear that there had been little or no reduction in cigarette attributable mortality in smokers who used light cigarettes as opposed to their so-called full flavour counterparts. ${ }^{41}{ }^{72}$ But the marketing of these products did appear to help the industry undermine cessation and prevention efforts and maintain a resilient pipeline of cigarette smokers who were no less likely to die prematurely than had they smoked the so-called regular brand counterparts of those cigarettes. ${ }^{916} 6773$

\section{1 st century marketing of claimed reduced risk tobacco} products

Renewed concerns about seemingly less toxic tobacco products being positioned as safer alternatives to conventional cigarettes (implicitly including light cigarettes) has emerged with the plethora of new tobacco products being marketed as reduced risk in recent years. ${ }^{74-77}$ These products include a mix of palladium containing genetically modified "cigarettes", lozenges made of tobacco powder and other materials, a carbon heated plastic and aluminum device that delivers glass fibres along with its nicotine, an electronically controlled nicotine delivery device, and other products. ${ }^{98-80}$

Some of these products are marketed aggressively with claims of relative safety and/or for use in situations in which smoking is not allowed ${ }^{81-89}$ For example, the smokeless tobacco products from Swedish Match, US Smokeless Tobacco, and the lozenge by Star Scientific are advertised for use when smoking is not allowed, including in the presence of children-for example, as described in Swedish Match (SmokeBreak@ myexhault.com) and Star (www.goariva.com) websites in May 2002. Thus, promotion of what has been termed "dual" tobacco product use to avoid the hassles of smoking restrictions, including for use around children, has the potential to foster even more persistent use. ${ }^{90} 91$

\section{Medications for harm reduction}

Medications could be used as supplementary sources of nicotine to reduce tobacco exposure, ideally as an interim step toward cessation. Conceptually, they would be used as a potentially better long term alternative to unmitigated tobacco toxin exposure. ${ }^{42-94}$ Because medications are strictly regulated by the FDA, their conditions of use (that is, indication and directions), their ingredients and design, and their manufacture receive extensive review before allowance of marketing. Furthermore, they can be removed from the market by the FDA if the FDA becomes concerned about a health problem or misrepresentation of the product in its labelling ("misbranding").95 Claims and marketing must be in accordance with FDA guidance or their marketing may be restricted, and the FDA might require the company to engage in corrective actions to address harms caused by the product or its marketing. ${ }^{95}$

Presently, the only approved indication for medications in the USA is as an "aid to smoking cessation". No other claims are permitted, and any application differing from that is considered "off label". Consumers are warned against concomitant use of the medications and tobacco. These conditions are not likely to change without a major commitment of pharmaceutical companies to develop new indications and without newfound flexibility by the FDA to accept such indications. ${ }^{4}$ In principle, medications developed and approved for harm reduction applications for adults could also benefit adolescents. However, the current situation with respect to treating adolescents with medications provides a sobering reminder of the magnitude of the challenge. Even though there are compelling logical reasons to use medications to treat tobacco addicted youth, the empirical base of supporting data is weak, and no medications have been approved for such use. ${ }^{55} 9697 \mathrm{In}$ fact, the labelling for the over-the-counter nicotine replacement products (nicotine gum and patches) prohibits their sale 
Table 2 Issues to be considered for various approaches to tobacco harm reduction (THR) ${ }^{98}$

\begin{tabular}{|c|c|c|c|}
\hline Issue & Description & Examples & Research and evaluation methods \\
\hline Intended effects & $\begin{array}{l}\text { What the THR approach aims to } \\
\text { achieve }\end{array}$ & $\begin{array}{l}\text { Reduce smoking, reduce toxic exposure from } \\
\text { smoking }\end{array}$ & $\begin{array}{l}\text { Toxicological-assessments of products and/or } \\
\text { human exposures; behavioural-reduced } \\
\text { smoking }\end{array}$ \\
\hline Mechanism & $\begin{array}{l}\text { How the approach is thought to } \\
\text { accomplish the intended effects }\end{array}$ & $\begin{array}{l}\text { Reduce smoking by reducing nicotine need } \\
\text { due to providing nicotine; reduce toxin } \\
\text { production by reducing burning temperature }\end{array}$ & $\begin{array}{l}\text { Toxicological-(reduced production); } \\
\text { behavioural-(reduced smoking) }\end{array}$ \\
\hline Potency & $\begin{array}{l}\text { Power of the mechanism, if it } \\
\text { works, to yield reduced harm }\end{array}$ & Cessation almost completely eliminates harm & $\begin{array}{l}\text { Medical-biological impact of use; } \\
\text { epidemiological-resulting disease impact }\end{array}$ \\
\hline Toxicology known & $\begin{array}{l}\text { Current state of knowledge } \\
\text { about the toxicology of the } \\
\text { approach or product }\end{array}$ & $\begin{array}{l}\text { Epidemiology of smokeless tobacco is } \\
\text { characterised; newly engineered products } \\
\text { have barely been characterised toxicologically, } \\
\text { and not at all epidemiologically }\end{array}$ & $\begin{array}{l}\text { Toxicological, medical, behavioural, and } \\
\text { epidemiological }\end{array}$ \\
\hline Toxicology complex & $\begin{array}{l}\text { Complexity of the toxicology, } \\
\text { due in part to complexity or } \\
\text { novelty of engineering in the } \\
\text { product/approach }\end{array}$ & $\begin{array}{l}\text { Reduction in smoking is simple, because the } \\
\text { toxic exposures are qualitatively unchanged, } \\
\text { but quantity is reduced. Newly-engineered } \\
\text { products, in contrast, may introduce new } \\
\text { toxins or interactions }\end{array}$ & $\begin{array}{l}\text { Toxicology-characterisation of new product, } \\
\text { including potentially new toxins and interactions }\end{array}$ \\
\hline Toxicity & $\begin{array}{l}\text { Remaining potential for toxicity, } \\
\text { even if harm is reduced }\end{array}$ & $\begin{array}{l}\text { Smokeless tobacco, even if less harmful than } \\
\text { smoking, is still harmful }\end{array}$ & Toxicology, medical, epidemiology \\
\hline Population risk & $\begin{array}{l}\text { Total population hazard, when } \\
\text { changes in adoption and } \\
\text { cessation of smoking are } \\
\text { considered }\end{array}$ & $\begin{array}{l}\text { Increased adoption of smoking if cigarettes } \\
\text { are perceived as "safe" may lead to increased } \\
\text { total harm }\end{array}$ & $\begin{array}{l}\text { Behavioural and epidemiological study of } \\
\text { impact on initiation and cessation, along with } \\
\text { toxicological evaluation of exposures }\end{array}$ \\
\hline Appeal & $\begin{array}{l}\text { Appeal to smokers, leading to } \\
\text { adoption }\end{array}$ & $\begin{array}{l}\text { Taste or inconvenience of some products may } \\
\text { deter adoption }\end{array}$ & $\begin{array}{l}\text { Behavioural and marketing studies of } \\
\text { preference; epidemiology of adoption }\end{array}$ \\
\hline Behaviour change & $\begin{array}{l}\text { The amount of behaviour } \\
\text { change smokers must make to } \\
\text { adopt the approach }\end{array}$ & $\begin{array}{l}\text { Smoking cigarette with different tobacco } \\
\text { requires little change; changing to smokeless } \\
\text { tobacco requires substantial change }\end{array}$ & Behavioural analysis \\
\hline Risk to others & $\begin{array}{l}\text { The risk (or change in risk) to } \\
\text { people other than the user }\end{array}$ & $\begin{array}{l}\text { Smokeless tobacco produces no sidestream } \\
\text { smoke, thus reducing environmental tobacco } \\
\text { smoke exposure }\end{array}$ & Toxicological analysis of byproducts \\
\hline Dependence & $\begin{array}{l}\text { Effect of the approach on } \\
\text { nicotine dependence }\end{array}$ & $\begin{array}{l}\text { Changing to smokeless tobacco likely to leave } \\
\text { dependence unchanged; no-nicotine cigarettes } \\
\text { unlikely to support dependence }\end{array}$ & $\begin{array}{l}\text { Pharmacological analysis of nicotine exposures; } \\
\text { behavioural and epidemiological assessment of } \\
\text { dependence }\end{array}$ \\
\hline
\end{tabular}

to persons under 18 years, and this situation is not likely to change in the near future.

\section{Harm reduction issues}

Shiffman and colleagues ${ }^{98}$ have assessed a wide range of factors that can be considered when evaluating the risks and benefits of a putative harm reduction strategy. As shown in table 2, it is possible to systematically apply a series of questions to a putative harm reduction approach, whether that approach involves a PREP or a behavioural strategy to reducing smoke intake. For example, an approach that offered little known reduction in toxicity over conventional tobacco products and a substantial risk of undermining prevention and cessation tobacco control efforts would appear to be of greater probable risk than benefit, than an approach that offered a high probability of toxin reduction without undermining prevention and cessation efforts.

\section{YOUTH TARGETED HARM REDUCTION: STRATEGIES AND ISSUES}

On the assumption that, in the foreseeable future, a substantial population of young people will continue to initiate tobacco use and develop addiction to tobacco delivered nicotine, we consider alternative approaches to reducing their risk of disease. This is the cornerstone goal for adult focused harm reduction. ${ }^{8}$ However, with respect to adolescents it would seem important to include an additional goal-namely, that the approach should not carry a high risk of addiction in its own right or a high risk of exacerbating addiction. Table 3 provides a summary of several potential harm reduction approaches and their plausible consequences if applied to youth. These approaches, and those discussed by Shiffman and colleagues, ${ }^{98}$ could be applied to adults but may pose potential risks to youth. Approaches that pose a particularly high risk to youth should therefore be considered with caution whether they are intended for youth or not.

\section{Comprehensive tobacco education and control}

Perhaps the least risky of all approaches are comprehensive education and tobacco control programmes that increase the awareness of the harmfulness of smoking and provide guidance with proven efficacy for refusing offers to smoke (for example, Wakefield and Chaloupka ${ }^{99}$ and American Legacy Foundation $\left.{ }^{100}\right)$. Such approaches, ordinarily referred to as "prevention", carry the potential benefit of reducing the progression from low levels of dependence to more severe levels and would not appear to exacerbate the dependence process. The underlying assumption is that the many factors that constitute comprehensive prevention could be implemented more effectively - for example, more effective dissemination of prevention education and more effective enforcement of supporting strategies such as reduced access to tobacco products. Systematic extension of educational efforts could explore messages intended to divert tobacco initiators from addiction to less frequent use and cessation. Federal legislation to support enforcement of youth access regulations could enhance such tobacco control efforts.

Behavioural strategies to reduce tobacco toxin exposure A tenant of FDA regulation is that labelling and advertising that affect how a product is used is regulated with equal importance as the physical nature of the product itself. In fact, labelling and instructions for product use are among the most actively negotiated aspects of drug product regulation. Surprisingly, to date there has been relatively little discussion of how labelling might lead to less hazardous tobacco product use or less frequent product use. Most extant discussion (for example, World Health Organization, Oslo, 2000) regarding labelling has addressed the warnings and ingredients. Yet the concept of reducing risk when engaged in hazardous activities through behavioural strategies is employed in sports, driving, alcoholic beverage consumption, and many other domains. With respect to cigarette smoking, Kozlowski ${ }^{101}$ developed a 


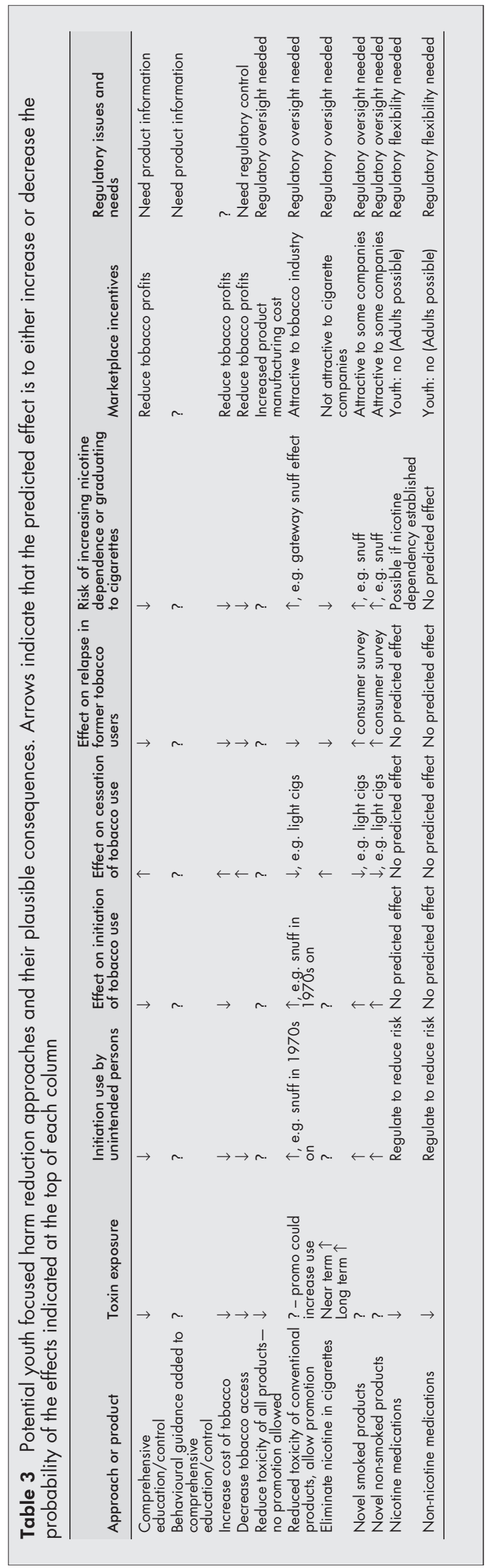

pamphlet titled Tar and nicotine ratings may be hazardous to your health: information for smokers who are not ready to stop, that was distributed by Canada's Addiction Research Foundation. This pamphlet included behavioural guidance such as advice for smoking cigarettes to reduce tar and nicotine yields by avoiding blocking the ventilation holes and taking fewer puffs. This was not targeted toward youth. Whether youth would tend to use such advice to reduce or to increase their exposure would undoubtedly depend on the nature of the information and its context, but such approaches could be developed and evaluated with an appropriate regulatory framework.

\section{Increased tobacco cost and decreased access}

Even though signs of dependence can occur in persons who do not use tobacco daily, intermittent smokers generally display substantially weaker and fewer signs of dependence than heavier smokers. ${ }^{52}{ }^{102}{ }^{103}$ Interventions such as increased cost (for example, through increased tax levels) and decreased access (for example, by more effective enforcement of prohibition of youth tobacco procurement) are logical strategies to mitigate the development and sustenance of dependence. These strategies can be implemented separately and "adjusted" separately, but in general it would appear that increasing cost and decreasing access would maximise the benefit. Of course, raising prices affects adults as well, but it appears that youth are more sensitive to the effects of price increases. ${ }^{104-106}$ Regulatory actions can also contribute to increase cost of the product at the point of purchase by minimal allowable package sizes; the proposed FDA regulation of tobacco banned small packages of cigarettes sometimes referred to as "kiddy packs". Such creative regulatory approaches to further increase the cost of tobacco products has the potential to reduce tobacco toxin exposure in continuing tobacco users and reduce the risk of progression to dependence following initiation.

\section{Reducing tobacco product toxicity with and without product promotion based on these reductions}

Reducing the toxicity of tobacco products without any promotion has the theoretical potential to reduce toxin exposure without increasing initiation or hindering cessation, providing that the primary message remains that the products are harmful and addictive and that some form of de facto promotion does not emerge (for example, a government endorsement that the product met new safety standards). Constraining promotion might prove to be more challenging than re-engineering the products. For example, media coverage of product alterations and the word-of-mouth spread of information about newly formulated products could emerge as forms of de facto promotion. Thus, effective regulation would be critical not only to set the standards and oversee the toxin reduction, but also to ensure that the process did not undermine prevention and cessation by reducing the concerns of young people about the products.

\section{Eliminating the nicotine from cigarettes}

Benowitz and Henningfield ${ }^{107}$ have discussed an approach to gradually eradicate the most harmful form of nicotine addiction - that is, cigarette smoking - by eliminating the nicotine in cigarettes over a period of 10-20 years to levels at which addiction could not be readily created or sustained. They hypothesised that while short term increases in tobacco toxins might be incurred by persons attempting to smoke more cigarettes to achieve desired nicotine levels, in the long run cigarette smoking would be reduced to an occasional behaviour in which nicotine addiction would not be a factor in the decision to smoke or not. Furthermore, it was predicted that if young people did begin to smoke cigarettes after the time that the nicotine levels had become insufficient to cause nicotine addiction, then their decision to quit smoking would 
not be compromised by the biological drive of nicotine addiction. A subsequent analysis, commissioned by the American Medical Association (AMA), ${ }^{108}$ considered some of the complexities of such a proposal including the need for comprehensive tobacco control policies and access to treatment. Absent the comprehensive approach discussed in the AMA report, such a strategy may have a variety of unintended consequences, such as increased tobacco smuggling, transfer to other forms of tobacco, and such strong social/political opposition that the strategy would be too short lived to demonstrate a health benefit as discussed by the authors of the report and elsewhere. ${ }^{109}$

\section{Novel products}

With respect to novel products, whether smoked or not, there are so many hypothetical considerations that any kind of prediction is difficult. If they fostered dependence with assurance of minimal risk, there is little reason to expect that persons would make strong efforts to resist the development of dependence or attempt to break it. Some smokers might require nicotine delivery systems that could provide nicotine more rapidly and in higher doses than current nicotine replacement medications, which could lead to products that are more hazardous and addictive than present products. Although the safety of pure nicotine forms that mimic cigarettes has not been evaluated, it is known that rapid delivery of even small doses of nicotine can produce strong cardiovascular and neuroendocrine effects that could contribute to heart disease. ${ }^{19}$

Another risk of these approaches is that unless they actually provided the same type of nicotine plasma spike as is provided by cigarettes, graduation to cigarette smoking could pose a serious risk as it does among US snuff users. ${ }^{29} 306291$ This risk appears to be a fundamental risk of addictive drugs in general in which there is a strong tendency to graduate from less aggressive to more aggressive forms of drug delivery, even when that form carries severe risks such as HIV contaminated heroin syringes or contaminated alcoholic beverages. ${ }^{15}$

\section{Medications}

Table 3 also considers the probable consequences of applying medications to youth to achieve harm reduction. Medications as partial substitutes for tobacco product exposure offer the possibility of "pure" nicotine delivery, with extensive regulatory oversight and a broad base of scientific safety evaluation. Even so, it is possible that nicotine medications could exacerbate the dependence process in youth who otherwise might not get addicted. It would be necessary to develop a validated method of limiting application to youth who are already hardcore smokers and at very high risk of sustaining their addictions. Non-nicotine medications would not necessarily carry this risk, but they carry their own risks that would similarly require an individualised risk-benefit evaluation. There are substantial regulatory, practical, and ethical barriers to developing medications for harm reduction treatment in youth that are discussed further on in this paper and elsewhere. ${ }^{45}$ In the near term, such approaches will likely be limited to specialty clinics and research settings such as at the Mayo Clinic and the National Institute on Drug Abuse. ${ }^{110} 111$

\section{Ethical issues specific to youth}

A core premise of regulation and truthful advertising and labelling is that research is conducted to determine effects and verify claims. As discussed in the IOM report, the research challenges confronting harm reduction product development are considerable. A focus on youth raises certain developmental and ethical issues specific to studies involving youth. ${ }^{111} 112$ For example, developmental and social aspects of adolescence, including attendance in school, often require modification of study designs. The fact that a potential target behaviour, namely tobacco use (or at least the procurement of tobacco), is one that may be considered illicit is a particular challenge from practical, ethical, and legal perspectives. The challenges will include developing acceptable methods from a scientific and ethical perspective, obtaining appropriate informed consent from participants and their legal guardians, providing appropriate compensation that does not constitute coercion, and enabling appropriate privacy and confidentiality to the participants. ${ }^{112}$

\section{REGULATORY FRAMEWORK}

A strong regulatory framework is critical to the success of many of the harm reduction approaches discussed in this paper. The development and marketing of light cigarettes and snuff provide deadly examples of exposure reduction gone awry in the absence of effective regulatory controls. The proliferation of 21 st century harm reduction products and promotion based on implied safety has reignited concerns by many health policy experts. The Campaign for Tobacco Free Kids, ${ }^{74-77}$ on behalf of a coalition of public health organisations, petitioned the FDA to regulate four of these products on the basis that there was substantial potential for public health harm and little chance of public health benefit absent appropriate regulation.

\section{Major regulatory loopholes}

A regulatory framework is crucial to ensure that products are true to their labelling (not "misbranded"), or there is no assurance that the products are as advertised. With respect to foods and drugs, claims such as "fresh", "reduced sodium", and "faster acting" must be supportable with data to the satisfaction of the regulatory agency. ${ }^{71}{ }^{95} 113$ Whereas there is a regulatory standard that assures consumers that Philip Morris' Light brand of Kraft cheddar cheese actually contains significantly less fat, there is no comparable assurance with respect to the same company's cigarette brands.

Prior approval of new tobacco products (including new brands) is a critical condition as well because it places the burden on the manufacturer to demonstrate that the product meets the conditions set by the agency or the product will not be marketed where it could cause decades of harm as did "light" cigarette brands. ${ }^{41}{ }^{114}$ Without the requirement of prior approval it would be practically impossible for the FDA to evaluate new products and then to initiate the time consuming and costly legal actions necessary to remove the products. Such regulatory oversight may well have prevented the apparent design or manufacturing problem which led to the glass fibre contamination of one of the novel smoking products. ${ }^{80} 115116$ In another example, the manufacturer of one of the current modified tobacco products acknowledges the use of palladium to trap certain toxins but provides no information regarding the safety of the palladium itself, and the product is being marketed aggressively on the basis of its implied health claims. ${ }^{69} 89$

\section{Institute of Medicine regulatory principles and surveillance needs}

The IOM report listed 11 regulatory principles as the foundation for a public health initiative to reduce the harms of tobacco use. ${ }^{9}$ These are summarised in table 4. With the exception of principle 7 , they would appear generally well suited to address major problems of the present regulatory vacuum. (We disagree with principle 7 and believe that the prior approval of all new products is critical for effective regulatory oversight of tobacco products that may reduce harm.) Whether these are the key principles or not, it is clear that a strong regulatory framework is essential to any harm reduction approach where there are commercial entities seeking to promote their versions of harm reduction. 
Table 4 Regulatory principles to strengthen federal regulation to govern the regulation of all potential reduced exposure products (PREPS) from the Institute of Medicine ${ }^{9}$

1. Manufacturers of tobacco products, whether conventional or modified, should be required to obtain quantitative analytical data on the ingredients of each of their products and to disclose such information to the regulatory agency

2. All tobacco products should be assessed for yields of nicotine and other tobacco toxicants according to a method that reflects actual circumstance of human consumption; when necessary to support claims, human exposure to various tobacco smoke constituents should be assessed using appropriate biomarkers. Accurate information regarding yield range and human exposure should be communicated to consumers in terms that are understandable and not misleading

3. Manufacturers of all PREPs should be required to conduct appropriate toxicological testing in preclinical laboratory and animal models as well as appropriate clinical testing in humans to support the health related claims associated with each product and to disclose the results of such testing to the regulatory agency

4. Manufacturers should be permitted to market tobacco related products with exposure reduction or risk reduction claims only after prior agency approval based on scientific evidence: (a) that the product substantially reduces exposure to one or more tobacco toxicants; and (b) if a risk reduction claim is made, that the product can reasonably be expected to reduce the risk of one or more specific diseases or other adverse health effects, as compared with whatever benchmark product the agency requires to be stated in the labelling. The "substantial reduction" in exposure should be sufficiently large that measurable reduction in morbidity and/or mortality (in subsequent clinical or epidemiological studies) would be anticipated, as judged by independent scientific experts

5. The labelling, advertising, and promotion of all tobacco related products with exposure reduction or risk reduction claims must be carefully regulated under a "not false or misleading" standard with the burden of proof on the manufacturer, not the government. The agency should have the authority and resources to conduct its own surveys of consumer perceptions relating to these claims

6. The regulatory agency should be empowered to require manufacturers of all products marketed with claims of reduced risk of tobacco related disease to conduct post-marketing surveillance and epidemiological studies as necessary to determine the short term behavioural and long term health consequences of using their products and to permit continuing review of the accuracy of their claims

7. In the absence of any claim of reduced exposure or reduced risk, manufacturers of tobacco products should be permitted to market new products without prior approval of the regulatory agency after informing the agency of the composition of the product and certifying that the product could not reasonably be expected to increase the risk of cancer, heart disease, pulmonary disease, adverse reproductive effects or other adverse health effects, compared to similar conventional tobacco products, as judged on the basis of the most current toxicological and epidemiological information

8. All added ingredients in tobacco products, including those already on the market, should be reported to the agency and subject to a comprehensive toxicological review

9. The regulatory agency should be empowered to set performance standards (for example, maximum levels of contaminants; definitions of terms such as "low tar") for all tobacco products, whether conventional or modified, or for classes of products

10. The regulatory agency should have enforcement powers commensurate with its mission, including the power to issue subpoenas. Exposure reduction and risk reduction claims for drugs that are supported by appropriate scientific and clinical evidence should be allowed by the FDA

In addition to regulatory principles, the IOM report concluded that the harm reduction approaches must be monitored for their effects on health and behaviour to enable detection of harms and thereby provide the basis for implementing corrective actions. The system will be challenged to detect events that could be relatively rare on a nationwide basis and it will need to be able to detect the problems in children and adolescents.

\section{Recommended fundamental regulatory principles}

The regulatory considerations discussed in the IOM and other reports merit further discussion (see Ferrence et $\mathrm{al}^{1{ }^{117}}$ Henningfield and Fant, ${ }_{118}^{18}$ Sweanor, ${ }^{119}$ Warner, ${ }^{6}$ Waxman, ${ }^{120}$ Rabin and Sugarman, ${ }^{121}$ WHO, ${ }^{114}$ Stratton et al, ${ }^{9}$ Slade and Henningfield, ${ }^{12}$ Henningfield and Slade, ${ }^{4}$ and Kessler and Myers ${ }^{122}$ ). For the purpose of the current analysis, however, we suggest that the following principles related to regulation are fundamental to consider whether the intended targets of harm reduction strategies are youth or adults.

(1) The FDA should be given the jurisdiction to effectively regulate all tobacco products-conventional and novelbecause no other agency has the broad range of critical expertise.

(2) The regulatory agency must have the same access to information about the products, ingredients, manufacturing techniques, marketing, and other factors related to safety and performance as it currently does for foods and drugs.

(3) New products and new ingredients and design modifications of existing products should not be marketed without prior regulatory approval.

(4) Products should be evaluated and appropriately regulated on the basis of their safety and addiction potential.

(5) Product evaluation should include predicted effects under conditions of actual use.

\section{CONCLUSIONS}

This paper has explored strategies for reducing the exposure to tobacco toxins so as to reduce the overall adverse health impact of tobacco. A key premise is that although the major adverse health impacts of tobacco occur in adults, strategies that might alter the trajectories of youth use from the most hazardous (persistent, high rate cigarette smoking) to less hazardous (shorter term and lower rate tobacco use) hold promise. A related premise is that strategies that undermine prevention and cessation efforts could lead to greater risks in individuals and populations even if those strategies included less hazardous forms of tobacco. The predicted effects would likely vary widely depending upon the strategy implemented and the regulatory environment required. Because of substantial areas of uncertainty raised in this paper, decision making will require a strong complement of supporting scientific research as discussed elsewhere. ${ }^{9123}$

It is technically feasible to partially replace nicotine delivered via cigarette smoke with nicotine from a novel source or a medication. To the extent that such an approach was correctly targeted to that relatively small population of youth that would have developed into hardcore tobacco dependent adults, it is possible that this approach might be of benefit. However, an approach that exacerbated nicotine addiction in other populations might yield overall negative public health consequences. Ensuring that harm reduction approaches primarily benefit their intended target populations without harming other populations is a major challenge and will require a framework for surveillance and regulatory oversight that does not presently exist. There are also practical and ethical challenges such as whether it is feasible to study a harm reduction product in adolescents adequately.

In addition to harm reduction approaches involving products, it is also feasible to consider the ways in which comprehensive tobacco control efforts could be extended beyond 
their traditional focus and position as "prevention" approaches and be modified to more specifically attempt to reduce tobacco toxin exposure and reduce the risk of developing addiction to nicotine. Such approaches would appear to be relatively low in risk, and most do not require elaborate new regulatory mechanisms because they are extensions of tobacco control efforts already in practice.

A range of youth focused harm reduction strategies are possible. Even those that appear to pose difficult regulatory and social challenges should not discarded too quickly, as it is possible that strategies that are unacceptable or considered inappropriate currently will be considered viable in another form or with the development of new technologies. For example, the concept of a 24 hour infusion of nicotine (now readily achieved with transdermal nicotine patches) was probably considered untenable, unacceptable, and unnecessary several decades ago when the seminal study was conducted to evaluate whether intravenous nicotine infusions could suppress smoking behaviour. ${ }^{124}$ Similarly, it is difficult to anticipate what doors may be opened by further research, by product development, and by creative new regulatory approaches. The challenges can appear daunting and the realities sobering, but perhaps more sobering is that on the current course, millions of today's adolescents will die prematurely of diseases caused by tobacco. This reality is certainly an impetus to consider more radical approaches than have been heretofore attempted.

\section{ACKNOWLEDGEMENTS}

Support was provided by an Innovators Combating Substance Abuse Award, from the Robert Wood Johnson Foundation to J Henningfield. The efforts of E. Moolchan were supported by the National Institute on Drug Abuse Intramural Research Program. We greatly appreciate the considerable assistance with references and editing provided by Ms Raluca Popovici and Christine A Rose, and assistance with figures and tables by Dr R Fant, whose efforts were partially supported by the Innovators Award to J Henningfield.

We would also like to acknowledge support of the Robert Wood Johnson Foundation's Research Network on the Etiology of Tobacco Dependence (TERN), from which has emerged a core concept of the present paper, namely that the uncertainties about determinants and predictors of the trajectory from first tobacco use to continued use or termination of use loom large in attempts to evaluate the risks and benefits of putative harm reduction approaches in youth.

$\mathrm{J}$ Henningfield and $\mathrm{M}$ Zeller have provided consulting services regarding treatments for tobacco dependence to GlaxoSmithKline Consumer Health Care through Pinney Associates. In addition, J Henningfield has a financial interest in a nicotine replacement product under development, and serves as an expert witness in litigation against the tobacco industry by the US Department of Justice and other plaintiffs. E Moolchan has received clinical supplies from GlaxoSmithKline Consumer Health Care to support a youth tobacco cessation study at the National Institute on Drug Abuse.

\section{Authors' affiliations}

J E Henningfield, Johns Hopkins University School of Medicine, Pinney Associates, Bethesda, Maryland, USA

E T Moolchan, Intramural Research Program, National Institute on Drug Abuse, Baltimore, Maryland, USA

M Zeller, Pinney Associates, Bethesda, Maryland, USA

\section{REFERENCES}

1 Substance Abuse and Mental Health Services Administration. Summary of findings from the 2000 National Household Survey on Drug Abuse. Rockville, Maryland, US Department of Health and Human Services. Office of Applied Studies, NHSDA Series H-13. 2001. (DHHS Publication No. (SMA) 01-3549).

2 Centers for Disease Control and Prevention. Projected smoking-related deaths among youth - United States. MMWR Morb Mortal Wkly Rep 1996:45:971-4.

3 Centers for Disease Control and Prevention. Trends in cigarette smoking among high school students - United States, 1991-2001. MMWR Morb Mortal Wkly Rep 2002;51:409-12.

4 Henningfield JE, Slade J. Tobacco dependence medications: public health and regulatory issues. Food and Drug Law Journal 1998;53:75-114.
5 Centers for Disease Control. Best practices for comprehensive tobacco control programs, August 1999. Atlanta, Georgia: US Department of Health and Human Services, Centers for Disease Control and Prevention, National Center for Chronic Disease Prevention and Health Promotion, Office on Smoking and Health, 1999.

6 Warner KE. Reducing harm to smokers: methods, their effectiveness, and the role of policy. In Rabin RL, Sugarman SD, eds. Regulating tobacco. New York: Oxford University Press, 2001.

7 Warner KE, Slade J, Sweanor DT. The emerging market for long-term nicotine maintenance. JAMA 1997;278:1087-92.

8 Warner KE, Peck CC, Woosley RL, et al. Treatment of tobacco dependence: innovative regulatory approaches to reduce death and disease: preface. Food and Drug Law Journal 1998;53(suppl): 1-8.

9 Stratton K, Shetty P, Wallace R, et al. Clearing the smoke: the science base for tobacco harm reduction-executive summary. Tobacco Control 2001;10:189-95

10 Giovino GA. Epidemiology of tobacco use in the United States. Oncogene 2002;21:7326-40

11 Pierce JP, Choi WS, Gilpin EA, et al. Tobacco industry promotion of cigarettes and adolescent smoking. JAMA 1998;279:51 1-5.

12 Slade J, Henningfield JE. Tobacco product regulation: context and issues. Food and Drug Law Journal 1998:53:43-74.

13 American Psychiatric Association. Diagnostic and statistical manual of mental disorders. Washington DC: American Psychiatric Association 1994.

14 World Health Organization. The ICD-10 classification of mental behavioural disorders. Geneva: World Health Organization, 1992.

15 O'Brien CP. Drug addiction and drug abuse. In: Hardman JG, Limbird $\mathrm{LE}$, Molinoff PB, et al, eds. Goodman \& Gilman's the pharmacological basis of therapeutics. New York: McGraw-Hill, 1996.

16 Henningfield JE, Schuh LM, Jarvik ME. Pathophysiology of tobacco dependence. In Bloom FE, Kupfer DJ, eds. Psychopharmacology: the fourth generation of progress. New York: Raven Press, 1995

17 Henningfield JE, Radzius A, Cone EJ. Estimation of available nicotine content of six smokeless tobacco products. Tobacco Control 1995;4:57-61

18 Royal College of Physicians. Nicotine addiction in Britain: a report of the Tobacco Advisory Group of the Royal College of Physicians. London: Royal College of Physicians of London, 2000.

19 Benowitz NL. Nicotine safety and toxicity. New York: Oxford University Press, 1998.

20 Covey LS. Nicotine dependence and its associations with psychiatric disorders: research evidence and treatment implications. Helping the hard-core smoker: a clinician's guide. Mahwah, New Jersey: Lawrence Erlbaum Associates, Publishers, 1999.

21 Downey KK, Pomerleau CS, Pomerleau OF. Personality differences related to smoking and adult attention deficit hyperactivity disorder. J Subst Abuse 1996:8:129-35.

22 Henningfield JE, Heishman SJ. Behavioral toxicology of nicotine. In: Benowitz NL, ed. Nicotine safety and toxicity. New York: Oxford University Press, 1998

23 Scollo M. Recreational nicotine: uncertain benefits and several major risks [comment]. Tobacco Control 2000;9:240-1.

24 Perry DC, Davila-Garcia MI Stockmeier CA et al. Increased nicotinic receptors in brains from smokers: membrane binding and autoradiography studies. J Pharmacol Exp Ther 1999;289:1545-52

25 Mansvelder HD, Keath JR, McGehee DS. Synaptic mechanisms underlie nicotine-induced excitability of brain reward areas. Neuron 2002;33:905-19.

26 Henningfield JE. Tobacco dependence treatment: scientific challenges; public health opportunities. Tobacco Control 2000;9(suppl I):i3-10.

27 Henningfield JE, Clayton R, Pollin W. Involvement of tobacco in alcoholism and illicit drug use. Br J Addiction 1990;85:279-91.

28 Kandel DB, Yamaguchi K. From beer to crack: developmental patterns of drug involvement. Am J Public Health 1993:83:851-5.

29 US Department of Health and Human Services. Preventing tobacco use among young people. A report of the Surgeon General, 1994. Atlanta, Georgia: Public Health Service, Centers for Disease Control and Prevention, Office on Smoking and Health, 1994. (US Government Printing Office Publication No S/N 017-001-00491-0.1

30 Lynch BS, Bonnie RJ, eds. Growing up tobacco free: preventing nicotine addiction in children and youths. Washington DC: National Academy Press, 1994.

31 US Department of Health and Human Services. The health consequences of involuntary smoking. A report of the Surgeon General, 1986. Rockville, Maryland: Public Health Service, Centers for Disease Control, 1986. (DHHS Publication No (CDC) 87-8398.)

32 Henningfield JE, Fagerstrom KO. Swedish Match Company, Swedish snus and public health: a harm reduction experiment in progress? Tobacco Control 2001;10:253-7.

33 Haddock CK, Weg MV, DeBon M et al. Evidence that smokeless tobacco use is a gateway for smoking initiation in young adult males. Prev Med 2001;32:262-7

34 Baker F, Ainsworth SR, Dye JT, et al. Health risks associated with cigar smoking. JAMA 2000;284:735-40.

35 US Department of Health and Human Services. Tobacco use among U.S. racial/ethnic minority groups: African Americans, American Indians and Alaska Natives, Asian Americans and Pacific Islanders, Hispanics. A report of the Surgeon General, 1998. Atlanta, Georgia: Centers for Disease Control and Prevention, Office on Smoking and Health, 1998. (US Government Printing Office Publication No S/N 017-001-00527-4.)

36 US Department of Health and Human Services. Reducing tobacco use. A report of the Surgeon General. Washington DC: US Government 
Printing Office, 2000. (US government Printing Offcie Publication No. S/N 017-001-00544-4.)

37 Moolchan ET, Berlin I, Robinson ML, et al. African-American teen smokers: issues to consider for cessation treatment. JNMA 2000;92:558-62.

38 Eissenberg T, Balster RL. Initial tobacco use episodes in children and adolescents: current knowledge, future directions. Drug Alcohol Depend 2000;59(suppl 1):S41-60.

39 Colby SM, Tiffany ST, Shiffman S, et al. Are adolescent smokers dependent on nicotine? A review of the evidence. Drug Alcohol Depend 2000:59(suppl 1):S83-95.

40 Shadel WG, Shiffman S, Niaura R, et al. Current models of nicotine dependence: what is known and what is needed to advance understanding of tobacco etiology among youth. Drug Alcohol Depend 2000;59:59-21.

41 National Cancer Institute. Risks associated with smoking cigarettes with low-machine measured yields of tar and nicotine. Smoking and Tobacco Control Monograph No. 13. 2001. Bethesda, Maryland: US Department of Health and Human Services, National Institutes of Health, National Cancer Institute. (NIH Publication No. 02-5074).

42 Mayhew KP, Flay BR, Mott JA. Stages in the development of adolescent smoking. Drug Alcohol Depend 2000;59(suppl 1):S61-81.

43 Choi WS, Ahluwalia JS, Harris KJ, et al. Progression to established smoking: the influence of tobacco marketing. Am J Prev Med 2002;22:228-33.

44 Farkas AJ, Distefan JM, Choi WS, et al. Does parental smoking cessation discourage adolescent smoking? Prev Med 1999:28:213-8.

45 Farkas AJ, Gilpin EA, White MM, et al. Association between household and workplace smoking restrictions and adolescent smoking. JAMA 2000;284:717-22.

46 Griffiths RR, Bigelow GE, Henningfield JE. Similarities in animal and human drug-taking behavior. In: Mello NK, ed. Advances in substance abuse. Greenwich, Connecticutt: JAI Press, Inc, 1980

47 Bachman JG, O'Malley PM, Schulenberg JE, et al. The decline of substance use in young adulthood: changes in social activities, roles, and beliefs. Mahwah, New Jersey: Lawrence Erlbaum Associates, 2002.

48 Kessler DA, Natanblut SL, Wilkenfeld JP, et al. Nicotine addiction: a pediatric disease. J Pediatr 1997:130:518-24.

49 Slade J. Adolescent nicotine use and dependence. Adolescent Medicine 1993;4:305-20

50 Abrams D B, Balster R, Collins LM, et al. The etiology of tobacco use: transdisciplinary theoretical framework to guide future research. 2002. Unpublished work.

51 White HR, Pandina RJ, Chen PH. Developmental trajectories of cigarette use from early adolescence into young adulthood. Drug Alcohol Depend 2002;65: 167-78.

52 Difranza JR, Rigotti NA, McNeill AD, et al. Initial symptoms of nicotine dependence in adolescents. Tobacco Control 2000; 9:313-9.

53 Prokhorov AV, Pallonen UE, Fava JL, et al. Measuring nicotine dependence among high-risk adolescent smokers. Addict Behav 1996;21:117-27.

54 Moolchan ET, Radzius A, Epstein DH, et al. The Fagerstrom test for nicotine dependence and the diagnostic interview schedule: do they diagnose the same smokers? Addict Behav 2002;27:101-13.

55 Henningfield JE, Michaelides T, Sussman S. Developing treatment for tobacco addicted youth - issues and challenges. Journal of Child \& Adolescent Substance Abuse 2000;9:5-26.

56 Doll R, Peto R. Cigarette smoking and bronchial carcinoma: dose and time relationships among regular smokers and lifelong non-smokers. J Epidemiol Community Health 1978;32:303-13.

57 Shopland DR, Burns DM. Medical and public health implications of tobacco addiction. In: Orleans CT, Slade J, eds. Nicotine addiction: principles and management. New York: Oxford University Press, 1993.

58 Henningfield JE, Fant RV, Tomar SL. Smokeless tobacco: an addicting drug. Advances in Dental Research 1997:11:330-5.

59 Connolly GN, Winn DM, Hecht SS, et al. The reemergence of smokeless tobacco. N Engl J Med 1986;314:1020-7.

60 Connolly GN. The marketing of nicotine addiction by one oral snuff manufacturer. Tobacco Control 1995;4:73-9.

61 Diordjevic MV, Hoffmann D, Glynn T, et al. U.S. commercial brands of moist snuff, 1994. I. Assessment of nicotine, moisture, and pH. Tobacco Control 1995;4:62-6.

62 Tomar SL, Giovino GA, Eriksen MP. Smokeless tobacco brand preference and brand switching among US adolescents and young adults. Tobacco Control 1995:4:67-72.

63 Walsh MM, Ellison J, Hilton JF, et al. Spit (smokeless) tobacco use by high school baseball athletes in California. Tobacco Control 2000;9/suppl II):ii32-39.

64 Ramström LM. Snuff - an alternative nicotine delivery system. In: Ferrence R, Slade J, Room R, Pope M, eds. Nicotine and public health. Washington DC: American Public Health Association, 2000.

65 Peeler LC. Cigarette testing and the federal trade commission: a historical overview. The FTC cigarette test method for determining tar, nicotine, and carbon monoxide yields of US cigarettes: report of the $\mathrm{NCI}$ Expert Committee. Bethesda, Maryland: US Department of Health and Human Services National Institutes of Health, National Cancer Institute, 1996: 1-8. (NIH Publication No 96-4028.)

66 Pillsbury HC. Review of the federal trade commission method for determining cigarette tar and nicotine yield. The FTC cigarette test method for determining tar, nicotine, and carbon monoxide yields of US cigarettes: report of the $\mathrm{NCl}$ Expert Committee. Bethesda, Maryland: US Department of Health and Human Services, National Institutes of Health, National Cancer Institute, 1996:9-14. (NIIH Publication No 96-4028.)
67 National Cancer Institute. The FTC cigarette test method for determining tar, nicotine, and carbon monoxide yields of US cigarettes: report of the $\mathrm{NCl}$ expert committee. Smoking and tobacco control monograph No 7. Bethesda, Maryland: US Department of Health and Human Services, National Institutes of Health, National Cancer Institute, 1996. (NIH Publication No 96-4028.)

68 Wilkenfeld J, Henningfield J, Slade J, et al. It's time for a change: cigarette smokers deserve meaningful information about their cigarettes. $J$ Natl Cancer Inst 2000;92:90-2.

69 National Cancer Institute. New cigarette advertisements reignite debate on safety. J Natl Cancer Inst 2002:94:160-1.

70 Shopland DR. Historical perspective: the low tar lie. Tobacco Control 2001;10(suppl I): i1-3

71 Food and Drug Administration, 21 CFR Part 801, et al. Regulations restricting the sale and distribution of cigarettes and smokeless tobacco products to protect children and adolescents; final rule. Federal Register 1996:61:44396-5318.

72 Thun MJ, Burns DM. Health impact of "reduced yield" cigarettes: a critical assessment of the epidemiological evidence. Tobacco Control 2001;10(suppl I):i4-11.

73 Giovino GA, Tomar SL, Reddy MN, et al. Attitudes, knowledge, and beliefs about low-yield cigarettes among adolescents and adults. The FTC cigarette test method for determining tar, nicotine, and carbon monoxide yields of US cigarettes: report of the NCI Expert Committee. Bethesda, Maryland: US Department of Health and Human Services, National Institutes of Health, National Cancer Institute, 1996: 39-57. (NIH Publication No 96-4028.)

74 National Center for Tobacco-Free Kids. Petition for regulation of R.J. Reynolds' "Eclipse" product in the Food and Drug Administration. Washington DC: 2001

75 National Center for Tobacco-Free Kids. Petition for regulation of Vector's "OMNI" cigarettes and Star Scientific's and Brown \& Williamson's "Advance" cigarettes in the Food and Drug Administration. Washington DC: 2001

76 National Center for Tobacco-Free Kids. Petition for regulation of Ariva Tobacco Lozenges in the Food and Drug Administration. Washington DC: 2001

77 National Center for Tobacco-Free Kids. Petition for regulation of S \& F Garet's nicotine water in the Food and Drug Administration. Washington DC: 2001

78 Slade J. Innovative nicotine delivery devices from tobacco companies. In: Ferrence R, Slade J, Room R, et al, eds. Nicotine and public health. Washington DC: American Public Health Association, 2000.

79 Henningfield JE, Rose CA, Slade J. New nicotine delivery devices: assessment using biomarkers. Presented at: Biomarkers for Tobacco Exposure: application to clinical and epidemiological studies. 26 October 2001. Minneapolis, Minnesota: University of Minnesota.

80 Reynolds T. New cigarette advertisements reignite debate on safety. J Natl Cancer Inst 2002;94:160-1.

81 Hwang SL. Accord system test widened by Philip Morris. The Wall Street Journal 17 September 1998, B5.

82 Hwang SL. Company's new effort to develop safer smoke uses special tobacco. The Wall Street Journal 29 April 1999, B1

83 Fairclough $\mathbf{G}$. Reynolds says eclipse cigarette may less likely cause cancer. The Wall Street Journal 20 April 2000.

84 Fairclough G. Philip Morris backs 'sensible' regulation. The Wall Street Journal Eastern 31 August 2000

85 Fairclough G. Smoking's next battleground: markers, health experts, debate whether 'safer' cigarettes are good or bad for public. The Wall Street Journal 2 October 2000.

86 Fairclough G. UST hopes its less-conspicuous products will convince smokers to switch to snuff. The Wall Street Journal, 22 January 2001

87 Fairclough G. 'Cigaleft' mints target customers who want alternative to cigarettes. The Wall Street Journal 27 April 2001.

88 Fairclough, G. Vector's new cigarette won't be safe. It may be safer, though. The Wall Street Journal, 25 June 2001

89 Fairclough, G. Vector reorganizes sales force to promote lower-risk smokes. The Wall Street Journal 11 March 2002, B2.

90 Henningfield JE, Rose CA, Giovino GA. Brave new world of tobacco disease prevention: promoting dual product use? Am J Prev Med 2002;23:226-8.

91 Tomar S. Snuff use and smoking in U.S. men: implications for harm reduction. Am J Prev Med 2002;23:143.

92 Shiffman S, Mason KM, Henningfield JE. Tobacco dependence treatments: review and prospectus. Annu Rev Public Health 1998:19:335-58.

93 Hughes JR. Reduced smoking: an introduction and review of the evidence. Addiction 2000;95 (suppl 1):S3-7.

94 Kozlowski LT. Harm reduction, public health, and human rights: smokers have a right to be informed of significant harm reduction options. Nicotine Tob Res 2002:4: S55-60.

95 Page JA. Federal regulation of tobacco products and products that treat tobacco dependence: are the playing fields level? Food and Drug Law Journal 1998;53(suppl I): 1 1-42.

96 Fiore MC, Bailey WC, Cohen SJ, et al. Treating tobacco use and dependence. Clinical practice guideline. Rockville, Maryland: US Department of Health and Human Services. Public Health Service, 2000

97 Mermelstein R. Youth smoking cessation. Tobacco Control 2003;12(suppl I):25-34.

98 Shiffman S, Gitchell JG, Warner KE, et al. Tobacco harm reduction: Conceptual structure and nomenclature for analysis and research. Nicotine Tob Res 2002; (suppl):S1 13-29. 
99 Wakefield M, Chaloupka F. Effectiveness of comprehensive tobacco control programmes in reducing teenage smoking in the USA. Tobacco Control 2000;9:177-86.

100 American Legacy Foundation. Using multiple strategies in tobacco use prevention education. Washington DC: American Legacy Foundation, 2002

101 Kozlowski LT. Tar and nicotine ratings may be hazardous to your health: information for smokers who are ready to stop. Toronto, Canada: Alcoholism and Drug Addiction Research Foundation, 1982.

102 Shiffman S. Tobacco "chippers" - individual differences in tobacco dependence. Psychopharmacology (Berl) 1989;97:539-47.

103 Centers for Disease Control and Prevention. Reasons for tobacco use and symptoms of nicotine withdrawal among adolescent and young adult tobacco users - United States, 1993. MMWR Morb Mortal Wkly Rep 1994:43:745-50.

104 Chaloupka FJ, Wakefield M, Czart C. Taxing tobacco: the impact of tobacco taxes on cigarette smoking and other tobacco use. In: Rabin RL, Sugarman SD, eds. Regulating tobacco. New York: Oxford University Press, 2001

105 Warner KE, Chaloupka FJ, Cook P, et al. Criteria for determining an optimal cigarette tax: the economist's perspective. Tobacco Control 1995;4:380-6.

106 World Bank. Curbing the epidemic: governments and the economics of tobacco control. Washington DC: World Bank, 1999.

107 Benowitz NL, Henningfield JE. Establishing a nicotine threshold for addiction. N Engl J Med 1994;331:123-5.

108 Henningfield JE, Benowitz NL, Slade J, et al. Reducing the addictiveness of cigarettes. Tobacco Control 1998;7:281-93.

109 Bates C, McNeill A, Jarvis M, et al. The future of tobacco product regulation and labeling in Europe: implications for the forthcoming European Union directive. Tobacco Control 1999;8:225-35.

110 Hurt RD, Dale LC, Offord KP, et al. Inpatient treatment of severe nicotine dependence. Mayo Clinic Proc 1992;67:823-8.

111 Moolchan ET, Ernst M, Henningfield JE. A review of tobacco smoking in adolescents: treatment implications. J Am Child Adolesc Psychiatry 2000;39:682-93.

112 Moolchan ET, Mermelstein R. Research on tobacco use among adolescents: ethical challenges. J Adolesc Health 2002;30:409-17
113 Food and Drug Administration, 21 CFR Part 801, et al. Food labeling: general provisions; nutrition labeling; label format; nutrient content claims; health claims; ingredient labeling; state and local requirements and exemptions; final rule. Federal Register 1993;58:2066-941.

114 World Health Organization. Advancing knowledge on regulating tobacco products. Geneva: World Health Organization, 2001.

115 Pauly JL, Cummings KM, Streck RJ. More about: safe cigarette alternatives? Industry critics say 'not yet'. J Natl Cancer Inst 2000;92:660.

116 Pauly JL, Lee HJ, Hurley EL, et al. Glass fiber contamination of cigarette filters: an additional health risk to the smoker? Cancer Epidemiology, Biomarkers Prevention 1998;7:967-79.

117 Ferrence R, Slade J, Room R, et al. Nicotine and public health. Washington DC: American Public Health Association, 2000.

118 Henningfield JE, Fant RV. Nicotine delivery systems: implications for abuse potential, medications development, and public health. In: Ferrence R, Slade J, Room R, et al, eds. Nicotine and public health. Washington DC: American Public Health Association, 2000.

119 Sweanor D. Regulatory mechanisms for nicotine delivering products: marketing and competition issues. In: Ferrence R, Slade J, Room R, et al, eds. Nicotine and public health. Washington DC: American Public Health Association, 2000.

120 Waxman HA. The future of the global tobacco treaty negotiations N Engl J Med 2002;346:936-9.

121 Rabin RL, Sugarman SD, eds. Regulating tobacco. New York: Oxford University Press, 2001

122 Kessler DA, Myers ML. Beyond the tobacco settlement. N Engl J Med 2001;345:535-7.

123 Hatsukami DK, Slade J, Benowitz NL, et al. Reducing tobacco harm: research challenges and issues. Nicotine Tob Res 2002;4:S89-101.

124 Lucchesi BR, Schuster CR, Emley GS. The role of nicotine as a determinant of cigarette smoking frequency in man with observations of certain cardiovascular effects associated with the tobacco alkaloid. Clin Pharmacol Ther 1967;8:789-96. 